\title{
Relançando o debate sobre o mutualismo no Brasil: as relações entre corporações, irmandades, sociedades mutualistas de trabalhadores e sindicatos à luz da produção recente.
}

Claudio H. M. Batalha*

Resumo: As sociedades mutualistas de trabalhadores no Brasil, entre meados do século XIX e as primeiras décadas do século XX, têm sido objeto de interpretações frequentemente diversas e conflitantes. Por um lado, parte dessas interpretações voltaram-se para essas sociedades como manifestações de uma forma particular de organização dos trabalhadores. Por outro lado, há interpretações que ressaltam o mutualismo como uma forma de seguro contra adversidades diversas, e em alguns casos adotou a teoria da escolha racional. Essa última abordagem fez da crítica à primeira uma de suas características. No entanto, longe de serem opostas essas duas abordagens conjuntamente contribuem de diferentes maneiras para o aprofundamento do conhecimento sobre as organizações da classe trabalhora e suas práticas.

Palavras chave: Mutualismo - Historiografia - Interpretações

Abstract: Working-class mutual aid societies in Brazil, between the mid-Nineteenth century and the first decades of the Twentieth century, have been subject to diverse and frequently conflicting interpretations. On the one hand, some of these interpretations have turned to these societies as a particular form of labor organization. On the other, are interpretations stressing the role of mutualism as a form of insurance against a number of risks, in some cases adopting the Rational Choice Theory. This last approach has been particularly critical on the first. Nevertheless, far from being opposed these two approaches can jointly contribute in different ways for further knowledge on working-class organizations and practices.

Key-Words: Mutual aid - Historiography - Interpretations

O livro de José Albertino Rodrigues, "Sindicato e desenvolvimento no Brasil" ${ }^{1}$, tem sido frequentemente criticado na produção recente, e não tão recente ${ }^{2}$, pela divisão em cinco fases que estabelece, no movimento sindical brasileiro. Inicia com a fase mutualista (antes de 1888), que é seguida pelas etapas de resistência (de 1888 a 1919), de ajustamento (de 1919 a 1934), de controle (de 1934 a 1945) e termina com a etapa competitiva (de 1945 a 1964). À sua cronologia é atribuída uma concepção teleológica, além da noção implícita de

\footnotetext{
* Este texto é um dos resultados do projeto "O sindicalismo 'amarelo' revisitado: novos estudos sobre o reformismo no movimento operário brasileiro (1880-1930)", bolsa de produtividade em pesquisa CNPq. Uma primeira versão foi apresentada durante o XXV Simpósio Nacional de História: História e Ética, ANPUH, Universidade Federal do Ceará (UFC), Fortaleza (CE), em julho de 2009.

* UNICAMP. E-mail: batalha@unicamp.br

${ }^{1}$ RODRIGUES, José Albertino. Sindicato e desenvolvimento no Brasil. São Paulo: Difel, 1968.

${ }^{2}$ Entre os quais, cf. DE LUCA, Tânia Regina. O sonho do futuro assegurado: o mutualismo em São Paulo. São Paulo: Contexto, 1990; LARA, Silvia. Escravidão, cidadania e história do trabalho no Brasil. Projeto História. São Paulo: PUC-SP, Vol.16, indicar a página inicial e a final do artigo, fev., 1998. e BATALHA, Claudio H. M. Sociedades de trabalhadores no Rio de Janeiro do século XIX: algumas reflexões em torno da formação da classe operária, Cadernos AEL. Campinas: AEL/IFCH/UNICAMP, Vol. 6, nso. 10-11,[s.m.], 1999.
} 
que o mutualismo constituiu uma fase precursora do sindicalismo, uma espécie de "préhistória". No entanto, durante muito tempo, sua concepção encontrou seguidores no Brasil. Victor Leonardi, por exemplo, ao tratar das origens do sindicalismo, também menciona a existência de uma fase mutualista, seguida por uma fase de resistência ${ }^{3}$. Perspectivas similares podem ser encontradas em outros contextos, como demonstrou Ronaldo Munck no caso argentino ${ }^{4}$.

Se a crítica à ideia de uma "pré-história" do movimento operário representada pelo mutualismo subjacente à divisão proposta por José Albertino Rodrigues, particularmente quando estabelece uma correlação entre a persistência da escravidão e o mutualismo, parece inteiramente pertinente, será que a ideia de que prevalece uma forma de organização operária no século XIX e outra depois, no século XX, é tão absurda assim?

Um aspecto pouco enfatizado, nesse autor, é que ele admite pensar a questão da organização dos trabalhadores em um quadro cronológico mais vasto e considera o mutualismo como parte integrante da história dos trabalhadores. Seria, portanto, um ato de justiça, mesmo que tardio, reconhecer-lhe o mérito do pioneirismo. Rodrigues, evidentemente, não estava interessado no mutualismo como fenômeno em si. Seu foco estava voltado para o mutualismo como forma de organização do operariado, uma questão essencial, mas que é, frequentemente, deixada de lado nas críticas a esse autor.

A produção acadêmica que, nos últimos anos, tem tratado das sociedades de auxílios mútuos adota dois enfoques distintos - em princípio, não contraditórios - para lidar com essas organizações. Um concebe o mutualismo como um fenômeno mais amplo e pluriclassista e o outro prefere interpretá-lo como uma das formas de organização dos trabalhadores. O primeiro privilegia a dimensão propriamente mutualista/previdenciária dessas organizações, ao passo que o segundo está mais atento para os aspectos que transcendem o mutualismo e que estão presentes nas intenções e nas práticas das associações.

Dessa primeira abordagem, são exemplos: Tânia Regina De Luca, Adhemar Lourenço da Silva Júnior, Cláudia Viscardi e Ronaldo Pereira de Jesus ${ }^{5}$. Esses autores, a despeito de diferenças no enfoque e na ênfase dada a certas questões, guardam em comum: a defesa do

\footnotetext{
${ }^{3}$ LEONARDI, Victor. Les origines du syndicalisme au Brésil. Paris: Université de Paris VIII, (Mémoire de maîtrise), 1971-1972.

${ }^{4}$ Cf. MUNCK, Ronaldo. Mutual benefit societies in Argentina: workers, nationality, social security and trade unionism. Journal of Latin American Studies. Cambridge: Cambridge University Press, 30 (3), out., 1998, p. 573.

${ }^{5}$ DE LUCA, Tânia Regina. O sonho do... op. cit.; SILVA JÚNIOR, Adhemar Lourenço da. As sociedades de socorros mútuos: estratégias privadas e públicas. Estudo centrado sobre o Rio Grande do Sul - Brasil, 1854-1940. Porto Alegre: PUC-RS, (Tese de doutorado), 2005. e VISCARDI, Cláudia Maria Ribeiro e JESUS, Ronaldo Pereira de. A experiência mutualista e a formação da classe trabalhadora no Brasil. In: FERREIRA, Jorge; REIS FILHO, Daniel Aarão (orgs.). As esquerdas no Brasil. Vol. 1, A formação das tradições (1889-1945). Rio de Janeiro: Civilização Brasileira, 2007.
} 
mutualismo como fenômeno amplo, diversificado e aberto a diferentes segmentos sociais; a crítica à concepção do mutualismo como predecessor dos sindicatos e a insistência na diferenciação e na ausência de vínculos entre as mutuais e outras formas organizativas, tais como as corporações de ofício, as irmandades leigas e os sindicatos.

$\mathrm{Na}$ segunda abordagem, apesar das diferenças entre os vários autores, estão presentes Claudio H. M. Batalha, Silvia Petersen, Beatriz Loner, Marcelo Badaró, Paula Nomelini, Rafaela Leuchtenberger, Osvaldo Maciel, Benito Schmidt, Alexandre Fortes, entre outros.

Não se pretende fazer, aqui, um balanço do conjunto, já significativo, da produção sobre o mutualismo nas últimas duas décadas - se fosse tomado como ponto de partida o livro pioneiro de Tânia De Luca, de 1990. Limitar-se-á a levantar algumas questões que dizem respeito às premissas da primeira dessas correntes interpretativas construídas em oposição, mais ou menos explícita, à segunda interpretação.

Não quero ser mal-entendido, nesse ponto. Considera-se perfeitamente legítimo que o mutualismo possa ser estudado como um fenômeno com sua própria lógica e não exclusivamente como forma de manifestação dos trabalhadores manuais em momentos em que outras formas de manifestação não estavam disponíveis. Todavia, o oposto também deveria ser verdadeiro. Não há porque cobrar que os estudos voltados primordialmente para a organização dos trabalhadores, analisem o mutualismo como um todo. Ou pretender, $a$ priori, que a lógica que preside o mutualismo dos trabalhadores seja, necessariamente, igual à das demais sociedades mutualistas.

Muitas das posições hoje defendidas no debate em torno do mutualismo e, mais particularmente, da relação do mutualismo dos trabalhadores com os sindicatos, já estavam presentes em "Sindicato e Estado" de Azis Simão, originalmente, publicado em 1966.

\section{As mutuais contribuíram para a emergência do movimento operário, de um modo geral, mas não deram origem ao sindicalismo que apareceu quase na mesma época. De fato, no arrolamento feito das sociedades de trabalhadores, apenas quatro grêmios daquela espécie precedem o surgimento das ligas operárias propriamente ditas. ${ }^{6}$}

O fato de Simão considerar as associações, de fins dos anos 1880 e dos anos 1890, como sendo sindicatos ajuda a entender sua interpretação. No levantamento das sociedades de cunho sindical que realiza, considera como a primeira delas o Centro Tipográfico Paulistano, que data de 1888, seguido da Società Cosmopolita fra Lavoratori Cappellai, de 1890. No primeiro caso, há uma impossibilidade jurídica, pois, sob a legislação de Império,

\footnotetext{
${ }^{6}$ SIMÃO, Azis. Sindicato e Estado: suas relações na formação do proletariado de São Paulo. 2ạ ed. São Paulo: Ática, 1981, p. 151.
} 
não era possível que uma organização se assumisse, abertamente, como um sindicato - e, mesmo o segundo caso, deve ser visto com cuidado ${ }^{7}$.

Tânia De Luca vai na mesma direção ao afirmar: "[...] é fundamental frisar que o mutualismo não deu origem nem se confunde com o sindicalismo" ${ }^{8}$. E, pouco depois: "Sindicalismo e mutualismo são, portanto, fenômenos contemporâneos e não excludentes, ainda que nem sempre seja possível demarcar fronteiras claras entre eles" ${ }^{\prime 9}$. No entanto, Luca admite que é possível encontrar sindicatos originados de sociedades de auxílios mútuos e que também há sindicatos que teriam passado a exercer atividades beneficentes.

Já na tese de doutorado de Adhemar Lourenço da Silva,

[...] as mutuais não são uma forma, por assim dizer, 'primitiva' de sindicalismo, e tampouco há evidências de que as primeiras se transformem e 'evoluam' para a segunda forma de associação. É certo que, de modo geral, as sociedades de socorros mútuos se constituíram antes dos sindicatos [...]. ${ }^{10}$

No artigo conjunto de Viscardi e Jesus, "A experiência mutualista e a formação da classe trabalhadora no Brasil", para explicar o motivo pelo qual o estudo das associações de socorros mútuos deveria abrir uma obra sobre a trajetória das esquerdas, os autores sustentam:

Em primeiro lugar, para afastar definitivamente a tese (sem comprovação empírica) de que as associações mutualistas, ou de socorro mútuo, constituíam uma espécie de proto-sindicalismo que mais tarde evoluiriam para a formação de associações de resistência no âmbito político das esquerdas. Em segundo lugar, para destacar, como vêm demonstrando as pesquisas mais recentes, que a experiência mutualista foi simultânea à organização dos sindicatos (inclusive os de esquerda) [... ${ }^{11}$

Nesse conjunto de passagens, encontram-se argumentos sobre o momento de surgimento de mutuais e de sindicatos e sobre a possível transformação de mutuais em sindicatos. Com exceção de Silva Jr., que admite, claramente, a antecedência cronológica das mutuais em relação aos sindicatos, há uma ambiguidade - aparentemente proposital - nos textos de Luca, Viscardi e Jesus ${ }^{12}$. Fenômenos "contemporâneos", diz Luca, e "simultâneo",

\footnotetext{
${ }^{7}$ Ibidem, p. 195.

${ }^{8}$ DE LUCA, Tânia Regina. O sonho do... op. cit. p. 10.

${ }^{9}$ Ibidem, p. 11.

${ }^{10}$ SILVA JÚNIOR, Adhemar Lourenço da. As sociedades... op. cit., p. 474.

${ }^{11}$ VISCARDI, Cláudia Maria Ribeiro e JESUS, Ronaldo Pereira de. A experiência... op. cit., pp. 24-25.

${ }^{12}$ É preciso reconhecer, nesse aspecto, porém, que as posições de Ronaldo Pereira de Jesus já foram mais matizadas em textos anteriores, como, por exemplo, "História e historiografia do fenômeno associativo no Brasil monárquico (1860-1887)", In: ALMEIDA, Carla Maria Carvalho de; OLIVEIRA, Mônica Ribeiro de (orgs.). Nomes e números: alternativas metodológicas para a história econômica e social. Juiz de Fora: Editora UFJF, 2006.; e na sua tese de doutorado, defendida, em 2001, publicada em livro com o título, cf. Idem. Visões da monarquia: escravos, operários e abolicionismo na corte. Belo Horizonte: Argvmentvm, 2009. Entretanto, a
} 
dizem Viscardi e Jesus, ou seja, de "quase na mesma época", segundo Azis Simão, o mutualismo e o sindicalismo passaram, implicitamente, para na mesma época. É possível, porém, que houvesse formas bem mais claras e menos ambíguas de dizer isso, que esses autores queiram apenas enfatizar a coexistência, a partir de um dado momento, e, por um longo período, de mutuais e de sindicatos. Se for essa a intenção, não se credita que haja, na produção recente, qualquer um que discorde dessa coexistência, ainda que possa existir alguma controvérsia sobre a duração dela. Todavia, se a intenção é pretender que as duas formas organizativas surgem, no Brasil, no mesmo momento, nem os casos de São Paulo e do Rio Grande do Sul, nos quais o período de tempo que as separa é menor do que em outros lugares, autorizam essa interpretação. As sociedades mutualistas - incluindo aquelas, exclusivamente, voltadas para trabalhadores - precederam, cronologicamente, por várias décadas, os sindicatos, não fosse por outro motivo, pela impossibilidade legal de se formar sindicatos durante o Império. Evidentemente, o fato de que, historicamente, as sociedades mutualistas precedem os sindicatos, não significa - como já foi amplamente demonstrado pela produção recente - que diversas mutuais não tenham sido criadas depois do surgimento dos sindicatos.

Estabelecido esse ponto, pode-se tratar do segundo aspecto que os autores associam a essa discussão, isto é, se os sindicatos derivam das sociedades mutualistas ou se as sociedades mutualistas de trabalhadores se transformaram em sindicatos. Na trilha de Azis Simão, tratando do caso de São Paulo, Luca, Silva Júnior e Viscardi e Jesus reafirmam que os sindicatos não teriam origem nas sociedades mutualistas. Porém, tanto Silva Júnior quanto Viscardi e Jesus admitem que há casos, ainda que raros, em que isso ocorre ${ }^{13}$. Convém ressaltar, em primeiro lugar, que não há quem sustente, hoje, que uma eventual transformação de sociedades mutualistas de trabalhadores em sindicatos constitua uma regra geral. Em segundo lugar, considerando o conhecimento existente sobre as transformações internas das sociedades mutualistas, na virada do século XIX para o XX, não é possível afirmar que essas transformações sejam raras. Pode-se apenas sustentar que há casos suficientemente documentados em que isso ocorreu. Não há dados quantitativos suficientes e confiáveis para poder estimar com que frequência houve a transformação.

A questão central nessa discussão, completamente ignorada pelos autores mencionados, é que, no século XIX, ou, pelo menos, durante o Império, diversas sociedades mutualistas foram mais do que mutualistas e cumpriram funções que poderiam ser

\footnotetext{
inflexão de suas posições já pode ser encontrada no artigo de: Idem. Mutualismo e desenvolvimento econômico. Revista OIDLES. 1, (1), set. 2007.

Disponível em: <http://www.eumed.net/rev/oidles/01/Pereira.htm>.

${ }^{13}$ Cf. SILVA JÚNIOR, Adhemar Lourenço da. As sociedades... op. cit., p. 24. e VISCARDI, Cláudia Maria Ribeiro e JESUS, Ronaldo Pereira de. A experiência... op. cit., p. 26.
} 
chamadas de sindicais, zelando por salários e condições de trabalho e empreendendo ações para alcançar suas reivindicações. Qual dúvida pode haver que a Associação Tipográfica Fluminense, ao dirigir a greve de 1858, estava empenhada em ações de cunho sindical, sem deixar de ser, legalmente, uma sociedade mutualista? Isso sem falar, ainda no Rio de Janeiro, dos casos clássicos da Associação de Socorros Mútuos Liga Operária, de 1870, e da Sociedade Corpo Coletivo União Operária, de 1880, cujos estatutos só foram aprovados pelo Conselho de Estado após alterações, por conterem disposições pouco compatíveis com os fins previstos para as sociedades mutualistas.

Não faltam exemplos, mesmo depois do Império, de sociedades que tinham uma natureza híbrida - mutualista, sindical e educativa -, como foi o caso da União Operária do Engenho de Dentro, de 1899; de sindicatos que asseguravam auxílios de caráter mutualista, como a União dos Operários Estivadores, de 1903, ou a União dos Chapeleiros do Rio de Janeiro, de 1910, e de sociedades mutualistas que se transformaram em sindicatos, como o Congresso União dos Operários em Pedreiras, de 1901. Diferentes combinações podem ser encontradas ao longo do tempo, muitas vezes, em uma mesma sociedade. A, já mencionada, Associação Tipográfica Fluminense, criada em 1853, como sociedade de socorros mútuos, mas que, em diversos momentos, desempenhou atividades sindicais e políticas, voltou a ser, durante a República, uma sociedade puramente mutualista ${ }^{14}$. Se todos esses exemplos são do Rio de Janeiro, parece provavel que situações similares também possam ser encontradas em lugares diversos. Em outras palavras, o risco de tipologias muito rígidas sobre a natureza das associações operárias é o de não dar conta da diversidade e da riqueza de realidades complexas.

A clara preocupação, em autores como Luca e Viscardi e Jesus, com a legislação na qual a organização das sociedades mutualistas se fundou, não corresponde à igual preocupação com o quadro jurídico e político mais amplo e, sobretudo, com as mudanças ao longo do tempo. Uma vez definida a natureza da sociedade de auxílios mútuos, ela parece ganhar um caráter inteiramente não-histórico nessa produção: uma vez que perpetua, de modo imutável, ao longo do tempo. As mudanças nas conjunturas, nas ordenações jurídicas, nos regimes políticos, na própria clientela das sociedades mutualistas permanecem distantes das preocupações. Não é por acaso que a palavra ruptura apareça uma única vez na tese de Silva Júnior e, ainda assim, quando critica o uso das rupturas da história política brasileira para periodizar o mutualismo ${ }^{15}$.

\footnotetext{
${ }^{14}$ Todos esses exemplos provém de BATALHA, Claudio H. M. (coord.). Dicionário do movimento operário - Rio de Janeiro do século XIX aos anos 1920: militantes e organizações. São Paulo: Editora Fundação Perseu Abramo, 2009.

${ }^{15}$ Cf. SILVA JÚNIOR, Adhemar Lourenço da. As sociedades... op. cit., p. 129.
} 
Separar as mutualistas dos sindicatos não é a única preocupação desses autores. Com argumentos similares, a separação é estendida para outras formas organizativas, como, por exemplo, as corporações de ofício e as irmandades. Desse modo, como no caso dos sindicatos, uma preocupação similar pode ser percebida em Azis Simão, que não encontra, no caso de São Paulo, a presença de corporações. Tal ausência o leva a afirmar: “Assim, os poucos padrões de associação corporativa transplantados para a região, antes mesmo de se fixarem e difundirem, diluíram-se meio século antes do primeiro surto industrial” ${ }^{16}$.

Viscardi e Jesus, por sua vez, recomendam que não se deva confundir sociedades mutualistas com irmandades leigas, com corporações de ofício, com filantropia e com seguradoras ${ }^{17}$. Aquilo que soa como plausível para o caso de São Paulo, na análise de Simão, é estendido para o restante do Brasil, inclusive para locais em que havia uma tradição artesanal mais antiga e consolidada, e que conheceram corporações de ofício e irmandades leigas vinculadas a ofícios, como Recife, Salvador e Rio de Janeiro. Considerando que, em Minas Gerais, há irmandades leigas desde o século XVIII ${ }^{18}$, não deixa de causar surpresa a afirmação de Cláudia Viscardi: “[...] é difícil imaginar que exista uma linha de continuidade entre irmandades e mutuais, pois ambas, pelo menos em Minas, também foram cronologicamente contemporâneas" ${ }^{19}$.

Se os pesquisadores, por vezes, têm dificuldades em perceber continuidades de práticas e de concepções de outras formas associativas, nas sociedades de auxílios mútuos, esse não era o caso dos contemporâneos, como demonstra o parecer do Conselho de Estado, de 9 de outubro de 1861, sobre os estatutos da Associação Nacional dos Artistas Brasileiros - Trabalho, União e Moralidade, vetando vários dos artigos, sob o argumento de que tendiam "restaurar o monopólio das antigas corporações dos ofícios ou artes" ${ }^{20}$. Viscardi e Jesus reconhecem que o caso dos estatutos dessa sociedade "excede em todos os itens os limites usuais do mutualismo", mas consideram que constitui a "exceção que confirma a regra" ${ }^{21}$. Quantas exceções serão necessárias para lançar dúvidas sobre a validade da regra?

A documentação disponível acerca das sociedades de auxílios mútuos, no século XIX, é extremamente exígua, ficando praticamente limitada a estatutos e a algumas poucas

\footnotetext{
${ }^{16}$ SIMÃO, Azis. Sindicato e... op. cit., p. 149.

${ }^{17}$ VISCARDI, Cláudia Maria Ribeiro e JESUS, Ronaldo Pereira de. A experiência... op. cit., pp. 24-26.

${ }^{18}$ A esse propósito, cf. BOSCHI, Caio César. Os leigos e o poder: irmandades leigas e política colonizadora em Minas Gerais. São Paulo: Ática, 1986.

${ }^{19}$ VISCARDI, Cláudia Maria Ribeiro. As experiências mutualistas em Minas Gerais: um ensaio interpretativo. In: ALMEIDA, Carla Maria Carvalho de; OLIVEIRA, Mônica Ribeiro de (orgs.). Nomes e... op. cit.

${ }^{20} \mathrm{~A}$ análise desse processo é desenvolvida por LACERDA, David Patricio. Na encruzilhada das solidariedades: a experiência mutualista entre os trabalhadores na Corte, 1860-1882. Campinas: Unicamp (Dissertação de mestrado em História), em andamento, cap. 3.

${ }^{21}$ VISCARDI, Cláudia Maria Ribeiro e JESUS, Ronaldo Pereira de. A experiência... op. cit., p. 45.
} 
publicações das próprias sociedades, referências esparsas na imprensa, processos de registro junto ao Conselho de Estado do Império ou às presidências das províncias. Portanto, dificilmente o conhecimento acumulado sobre essas sociedades possibilita ter uma ideia precisa do seu funcionamento interno, das disputas e dos debates que as atravessavam. Nesse sentido, é necessário avaliar, com cuidado, a documentação disponível e buscar, nessa documentação, os aspectos de diferenciação com relação a outras sociedades de caráter similar. $O$ exame de alguns dos estatutos revela evidências suficientemente consistentes para afirmar em que medida sociedades mutualistas se aproximavam ou se distanciavam de outras modalidades associativas. Ainda que, juridicamente, as distinções pudessem ser claras - mais no Império do que na República - as intenções afixadas, as evidências das práticas associativas e o posicionamento público diante de determinadas questões (a concorrência de produtos estrangeiros, os salários, o trabalho escravo, a abolição) mostram nítidas diferenças entre o estatuto jurídico assumido (a condição de sociedade mutualista) e a presença disfarçada de práticas que remetem às irmandades, às corporações de ofício ou aos sindicatos. Nunca é demais lembrar que, no período imperial, a opção pela forma jurídica de sociedade mutualista não era uma questão de escolha, mas, sim, a única forma de organização legal disponível para trabalhadores.

Com a tese de doutorado de Marcelo Mac Cord, tem-se a análise competente de um conjunto documental, até agora único, que, aliado a outras fontes, permitiu ao autor acompanhar, durante décadas, as atividades e os debates internos de uma sociedade de artífices no Recife oitocentista ${ }^{22}$. Pela primeira vez há um caso documentado, de uma longa convivência e de relações endógenas entre uma sociedade formalmente mutualista e uma irmandade de um santo padroeiro de ofício. Ao mesmo tempo, práticas, ritos e hierarquias de corporação de ofício vigoram na sociedade mutualista. É evidente que não se pode pretender que a trajetória da Sociedade dos Artistas Mecânicos e Liberais do Recife tenha sido seguida por todas as sociedades mutualistas voltadas para trabalhadores. Entre outras coisas, parece pouco provável que a capacidade de articulação política demonstrada por essa sociedade, na obtenção de obras públicas e de outros benefícios do poder público, possa ser estendida para muitas outras sociedades mutualistas. Feitas essas ressalvas, recomendadas pela prudência, a tese de Mac Cord abala muitas das certezas estabelecidas sobre o mutualismo no Brasil imperial e, consequentemente, lança a semente da dúvida sobre certezas que, fundadas em classificações jurídicas, levam à dedução de práticas.

Há, ainda, alguns aspectos centrais da tese de Adhemar da Silva Jr. que merecem ser mencionados na medida em que deixaram de ser opções metodológicas do autor - que tem

\footnotetext{
${ }^{22}$ MAC CORD, Marcelo. Andaimes, casacas, tijolos e livros: uma associação de artífices no Recife, 1836-1880. Campinas: UNICAMP, (Tese, doutorado em história), 2009.
} 
todo direito de adotar o enfoque que julgar apropriado - para se tornarem eixos do debate em torno da produção sobre o mutualismo que ele propõe. Dois desses aspectos são indissociáveis: a distinção entre estratégias privadas e públicas e o uso da teoria da escolha racional. A inspiração imediata provém dos estudos de Marcel van der Linden ${ }^{23}$ sobre o tema com algumas diferenças importantes, uma vez que esse autor não sustenta que sociedades organizadas por trabalhadores sejam iguais a outras mutualistas. A abrangente e volumosa coletânea organizada por Linden, uma das principais referências para a discussão atual do mutualismo, volta-se para o mutualismo operário, reconhecendo especificidades na mutualidade operária que alguns dos seus seguidores brasileiros tendem a negar. Esse autor, tampouco, rompe com a noção de identidade, duramente criticada por Adhemar da Silva $\mathrm{Jr}^{24}$. A teoria da escolha racional também provém de outros autores - ainda que nem sempre apareça sob essa denominação - como Mancur Olson, Albert O. Hirschman e Adam Przeworski. De forma simplificada, essa teoria parte do pressuposto de que a adesão de um indivíduo a uma dada sociedade se dá mediante uma análise dos prós e dos contras desse ato, dos ganhos que essa adesão trará. Evidentemente, é uma abordagem indissociável da ideia de que sociedades mutualistas são, exclusivamente, entidades de caráter previdenciário, às quais indivíduos aderem como forma de proteção contra eventuais dificuldades. Isso não significa apenas não reconhecer que, sob a forma de sociedades mutualistas, possam existir práticas e tomadas de posição mais próximas das corporações de ofício, das irmandades ou dos sindicatos. Além disso, também não se reconhece que essas sociedades possam ser encaradas sob outros aspectos por seus aderentes, por exemplo, como forma de sociabilidade essencial para a integração dos imigrantes recém-chegados, como propõe Ronaldo Munck para o caso argentino ${ }^{25}$.

O problema central dessa teoria é sua dificuldade em reconhecer a diversidade de racionalidades, reduzindo a racionalidade a decisões de cunho econômico e contábil do ponto de vista do indivíduo. Grupos, movimentos e instituições podem tomar decisões que não são irracionais do ponto de vista de sua própria lógica, mas que não se enquadrariam

\footnotetext{
${ }^{23}$ LINDEN, Marcel van der. (org.). Social security mutualism: the comparative history of mutual benefit societies. Berna/Berlim/Frankfurt/Nova lorque/Paris/Viena: Peter Lang, 1996. Ver, em particular, a introdução. Ver a argumentação desenvolvida no texto em coautoria com LUCASSEN, Jan. Prolegomena for a global labour history. Amsterdã: International Institute of Social History, 1999. Disponível em: <http://www.iisg.nl/research/prolehtml.php\#3>. E, ainda, mais recentemente, ver a parte "Varieties of Mutualism" de LINDEN, Marcel van der. Workers of the world: essays towards a global labor history. Leiden/Boston: Brill, 2008.

${ }^{24}$ Além das críticas já contidas em sua tese, novos argumentos são arrolados em SILVA JÚNIOR, Adhemar Lourenço. "A associação de trabalhadores difere daquela dos demais seres humanos?”, texto apresentado no I Seminário Internacional de Histório do Trabalho - V Jornada Nacional de História do Trabalho, Universidade Federal de Santa Catarina, Florianópolis, 25-28 de outubro de 2010.

${ }^{25}$ MUNCK, Ronaldo. Mutual benefit... op. cit., p. 588.
} 
em uma racionalidade contábil. Aquilo que Edward Thompson batizou de "economia moral da multidão" é um exemplo apropriado disso. São escolhas resultantes de crenças, costumes e moral perfeitamente racionais, na lógica daqueles que as tomam, porém distante de qualquer tipo de racionalidade "contábil".

Com argumentos próximos aos de Silva Jr, mas, com alguns matizes, tanto Jesus quanto Viscardi, individualmente e em conjunto, sugerem que se as sociedades mutualistas de trabalhadores tiveram um papel na construção de uma identidade de classe, toda e qualquer sociedade mutualista possuía uma função similar na construção de identidades ${ }^{26}$. Concorda-se, completamente, com a ideia de que o associativismo, de forma geral, contribui para reforçar os laços identitários, porém é preciso cuidado para não inferir que as formas como as identidades são construídas são idênticas, ou mesmo, que, em sociedades de um mesmo tipo e voltadas para uma mesma clientela, isso ocorra do mesmo modo. Se, como têm demonstrado diversos autores, como, por exemplo, Luigi Biondi ${ }^{27}$, para uma parcela significativa dos imigrantes italianos foi, no Brasil, que, de fato, eles passaram a se pensar como italianos, e formas associativas como as sociedades mutualistas auxiliaram nesse processo, pode-se concluir que isso provavelmente também ocorreu com outras identidades nacionais em processo de constituição. No entanto, seria absurdo supor que identidades nacionais já consolidadas, como a de portugueses ou a de franceses, dependessem da participação em sociedades étnicas, para se sentirem mais portugueses ou mais franceses. Um raciocínio similar pode ser usado para o caso das sociedades de trabalhadores. Sociedades mutualistas por ramo de produção ou por ofício podiam servir para reforçar uma identidade de ofício e, sobretudo, interesses coletivos do ofício, mas é altamente improvável que um marceneiro se sentisse mais marceneiro por participar de uma associação do seu ofício. Pode-se afirmar, como Marcel van der Linden, que as sociedades mutualistas, em geral, ajudaram os trabalhadores a adquirir a capacidade de organização, "civilizando" a classe operária $^{28}$. São, porém, poucas as sociedades mutualistas de trabalhadores que contribuíram, mais diretamente, para a construção de uma identidade de classe, essencial no processo de formação da classe operária.

Não pretendo com essa contribuição ao debate, contrapor uma forma de estudo do mutualismo à outra. Ambas são necessárias e pertinentes. Não se percebe nenhuma

\footnotetext{
${ }^{26}$ Cf. JESUS, Ronaldo Pereira de. Mutualismo e... op. cit.; VISCARDI, Cláudia Maria Ribeiro. Mutualismo e filantropia. Locus : Revista de História. Juiz de Fora, 10 (1), jan.- jun. 2004, Disponível em: <http://www.ufjf.br/locus/files/2010/02/Mutualismo-e-Filantropia.pdf>. e VISCARDI, Cláudia Maria Ribeiro e JESUS, Ronaldo Pereira de. A experiência... op. cit., p. 27.

${ }^{27}$ BIONDI, Luigi. Entre associações étnicas e de classe: os processos de organização política e sindical dos trabalhadores italianos na cidade de São Paulo, 1890-1920. Campinas: UNICAMP, (Tese, doutorado em História), 2002.

${ }^{28}$ LINDEN, Marcel van der. Introduction. In: Ibidem, (org.). Social security... op. cit.
} 
oposição irreconciliável entre uma perspectiva que enfatiza a relação das sociedades mutualistas de trabalhadores com a história mais ampla do trabalho e aquela voltada, primordialmente, para o fim previdenciário do mutualismo. Pelo contrário, percebe-se uma complementaridade. Não faltam exemplos de autores, como, por exemplo, Michel Ralle ${ }^{29}$, que conseguem, em seus estudos, conciliar essas duas perspectivas. Há muito ainda a ser feito na pesquisa sobre a história do mutualismo, no Brasil, mas, certamente, têm-se a ganhar se forem deixadas de lado oposições dicotômicas e certezas absolutas.

Recebido em 15/12/2010

Aceito para publicação em 20/12/2010

\footnotetext{
${ }^{29}$ Ver, por exemplo, RALLE, Michel." A função da proteção mutualista na construção de uma identidade operária na Espanha (1870-1910)", Cadernos AEL. Campinas: [s.e.], Vol. 6, nos. 10-11,[s.m.], 1999.
} 